\title{
. \\ An update of consensus guidelines for warfarin reversal
}

\section{Huyen A Tran MB BS, MClinEpi, FRACP, Haematologist ${ }^{1,2}$ \\ Sanjeev D Chunilal MB ChB, FRACP, FRCPA, Haematologist ${ }^{2}$ \\ Paul L Harper MD, FRCP, FRACP, Haematologist $^{3}$}

Huy Tran MB BS, FRACP, FRCPA Clinical and Laboratory Haematologist ${ }^{4}$

Erica M Wood MB BS, FRACP, FRCPA Haematologist $2,5,6$

Alex S Gallus MB BS, FRACP FRCPA Haematologist, ${ }^{7}$ and Professor of Haematology 8

on behalf of the Australasian Society of Thrombosis and Haemostasis

1 Clinical Haematology, The Alfred Hospital, Melbourne, VIC.

2 Haematology,

Monash Medical Centre Melbourne, VIC.

3 Clinical Haematology, Palmerston North Hospital.

Palmerston North, New Zealand.

4 Haematology,

Dorevitch Pathology, Melbourne, VIC.

5 Diagnostic Haematology, Royal Melbourne Hospital, Melbourne, VIC.

6 Monash University, Melbourne, VIC.

7 Haematology, SA Pathology at Flinders Medical Centre, Adelaide, SA.

8 Flinders University, Adelaide, SA.

huyen.tran@ monash.edu

doi: 10.5694/mjal2.10614

An abridged version of
this article appeared in
the printed journal

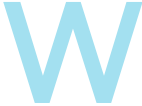
arfarin is effectively used in a wide range of thromboembolic disorders for primary and secondary prevention. Patients on long-term therapy have a risk of 1\%-3\% per year for haemorrhage leading to hospitalisation or death. ${ }^{1,2}$ Therefore, strategies to manage over-warfarinisation and warfarin during invasive procedures are important. ${ }^{3,4}$ Despite the associated bleeding risk, warfarin remains the most commonly prescribed anticoagulant in Australia and New Zealand. Common indications for the use of warfarin in the community include stroke prevention in atrial fibrillation $(\mathrm{AF})$, preventing thrombus formation in patients with mechanical heart valves (MHV), and treatment of venous thromboembolism (VTE). For most warfarin indications, the target international normalised ratio (INR) is 2.03.0 (VTE and single MHV excluding mitral). For mechanical mitral valve or combined mitral and aortic valves, the target INR is $2.5-3.0 .^{5} \mathrm{New}$ anticoagulants such as oral direct factor Xa inhibitors and direct thrombin inhibitors are becoming available as alternatives to warfarin. ${ }^{6-8}$ However, it is likely that warfarin will continue to be widely used in the community among patients who are already stable on warfarin or have severe renal impairment (creatinine clearance, $<30 \mathrm{~mL}$ / min), and for anticoagulation indications for which these novel agents have not been evaluated, such as MHV.,10

This update of the previous consensus guidelines ${ }^{11}$ is again on behalf of the Australasian Society of Thrombosis and Haemostasis (ASTH) and offers advice on strategies to prevent over-anticoagulation, the principles of warfarin reversal, and bridging anticoagulation therapy in different clinical settings. In particular, the focus is on managing:

- warfarin therapy complicated by bleeding;

- a supratherapeutic INR with no bleeding; and

- warfarin therapy during invasive procedures.

The recommendations draw on available evidence and the clinical experience of the panel of author-practitioners.

\section{Guideline development}

As Australian and New Zealand-based experts in the field of thromboembolic disorders, we were invited to join the panel leading guideline development. The process included reviewing up-to-date evidence and existing highquality evidence-based international guidelines for warfarin reversal. We conducted a face-to-face meeting on 21 March 2011 at which specific questions and drafting of the guidelines were discussed. Further revisions were made by consensus via email. All six members of the panel are the authors of this article.

\section{Summary \\ - Despite the associated bleeding risk, warfarin is the most commonly prescribed anticoagulant in Australia and New Zealand. Warfarin use will likely continue for anticoagulation indications for which novel agents have not been evaluated and among patients who are already stabilised on it or have severe renal impairment. \\ - Strategies to manage over-warfarinisation and warfarin during invasive procedures can reduce the risk of haemorrhage. \\ - For most warfarin indications, the target international normalised ratio (INR) is 2.0-3.0 (venous thromboembolism and single mechanical heart valve excluding mitral). For mechanical mitral valve or combined mitral and aortic valves, the target INR is 2.5-3.5.}

- Risk factors for bleeding with warfarin use include increasing age, history of bleeding and specific comorbidities.

- For patients with elevated INR (4.5-10.0), no bleeding and no high risk of bleeding, withholding warfarin with careful subsequent monitoring seems safe.

- Vitamin $K_{1}$ can be given to reverse the anticoagulant effect of warfarin. When oral vitamin $\mathrm{K}_{1}$ is used for this purpose, the injectable formulation, which can be given orally or intravenously, is preferred.

- For immediate reversal, prothrombin complex concentrates (PCC) are preferred over fresh frozen plasma (FFP). Prothrombinex-VF is the only PCC routinely used for warfarin reversal in Australia and New Zealand. It contains factors II, IX, X and low levels of factor VII. FFP is not routinely needed in combination with Prothrombinex-VF. FFP can be used when Prothrombinex-VF is unavailable. Vitamin $\mathrm{K}_{1}$ is essential for sustaining the reversal achieved by PCC or FFP.

- Surgery can be conducted with minimal increased risk of bleeding if INR $\leqslant 1.5$. For minor procedures where bleeding risk is low, warfarin may not need to be interrupted. If necessary, warfarin can be withheld for 5 days before surgery, or intravenous vitamin $\mathrm{K}_{1}$ can be given the night before surgery. Prothrombinex-VF use for warfarin reversal should be restricted to emergency settings. Perioperative management of anticoagulant therapy requires an evaluation of the risk of thrombosis if warfarin is temporarily stopped, relative to the risk of bleeding if it is continued or modified.

We based our recommendations on the body of evidence, with consideration of the strength of evidence, consistency across studies, likely clinical impact, and generalisability and applicability of study findings in the local setting. 
Relevant clinical questions guided systematic review of the evidence. We followed the GRADE (Grading of Recommendations Assessment, Development and Evaluation) method to generate recommendations. The strength of recommendations, designated strong (1) or weak (2), is based on the quality of the body of evidence, which can be high (A), moderate (B) or low (C). ${ }^{12}$ For recommendations where the quality of evidence was not sufficient to allocate a grade, the term "good practice point" (GPP) indicates the recommendation is based on the consensus opinion of the ASTH writing panel (Box 1). Consensus recommendations were reached in an equitable manner. Agreement of all members of the expert panel was required in order to proceed with making the recommendation.

Potential conflicts of interest were declared and recorded. Funding for this update was provided by a restricted educational grant from CSL Bioplasma that was administered by the ASTH.

\section{Bleeding complications of warfarin therapy}

Bleeding is the most common complication of warfarin therapy and is related to the INR value. Although incremental rises in INR increase the risk of bleeding, most intracranial bleeds are in patients with an INR in the therapeutic range; they occur in $0.5 \%-1.0 \%$ of patients with $\mathrm{AF}$ per year. ${ }^{13,14}$ Bleeding risk is also related to patient factors including age, a prior bleeding history and specific comorbidities. Elderly patients are generally more sensitive to warfarin and need a lower mean daily dose. ${ }^{15,16}$ Bleeding risk is greatest in the first 3 months after starting warfarin. An occurrence suggests an underlying organspecific lesion and should be appropriately investigated. ${ }^{1,17}$

Changes in concomitant medication potentially alter a patient's response to warfarin anticoagulation and increase their risk of bleeding. Drugs that commonly alter warfarin metabolism include antibiotics, amiodarone, statins, anticonvulsants and some herbal medications, such as St John's wort. Alcohol in small to moderate amounts probably has little effect on warfarin metabolism. Among heavy drinkers, however, associated factors such as increased falls, alcoholinduced gastritis, poor diet and poor compliance all increase the risk of bleeding. Bleeding prediction scores, such as HAS-BLED (hypertension, abnormal liver or renal function, stroke, bleeding history or predisposition, labile INR, elderly [>65 years], alcohol or drugs concomitantly) for AF, may help to identify factors that can be modified to reduce the risk of warfarin-related bleeding but should not result in withholding of anticoagulation therapy. ${ }^{18}$

General principles for preventing high INR include careful therapeutic monitoring and adopting other precautionary measures that can minimise bleeding risk due to high INR (Box 2). ${ }^{19-22}$

\section{Warfarin reversal}

\section{Vitamin $\mathrm{K}_{1}$ for reversal of warfarin-associated coagulopathy}

Vitamin $K_{1}$ is an effective antidote to the anticoagulant effect of warfarin. Despite this, data are lacking to show
1 Grades of guideline recommendations
Grade of recommendation

Strong recommendation,

high-quality evidence (1A)

Strong recommendation, moderate-quality evidence (1B)

Strong recommendation, low-quality evidence (1C)

Weak recommendation, high-quality evidence (2A)

Weak recommendation, moderate-quality evidence (2B) Weak recommendation, low or very low-quality evidence (2C)

Good practice point (GPP)

\section{Quality of supporting evidence}

Evidence obtained from a systematic review of all relevant randomised controlled trials (RCTs) or exceptionally strong evidence from observational studies

Evidence from at least one RCT or very strong evidence from observational studies

Evidence for at least one critical outcome from observational studies, case series, or RCTs, with serious flaws or indirect evidence

Evidence obtained from a systematic review of all relevant RCTs or exceptionally strong evidence from observational studies

Evidence from at least one RCT or very strong evidence from observational studies

Evidence for at least one critical outcome from observational studies, case series, or RCTs, with serious flaws or indirect evidence

Supporting evidence is insufficient to meet even the lowest grade of evidence. Recommendation is therefore based on consensus opinion of the writing panel of Australasian Society of Thrombosis and Haemostasis

\section{Principles for preventing high international normalised ratio (INR)*}

- When starting warfarin therapy, avoid high loading doses of warfarin. In general, it is preferable to start treatment using an initial daily dose of $5 \mathrm{mg}$, or even lower in elderly patients. ${ }^{19-21}$ However, some guidelines have suggested that patients who are considered sufficiently healthy may receive warfarin $10 \mathrm{mg}$ daily for the first 2 days with subsequent doses to be determined by the INR (2C) $)^{12}$

- Consider potential warfarin-drug interactions. Avoid concomitant non-steroidal antiinflammatory drugs and certain antibiotics (2C). Avoid concomitant antiplatelet therapy except where clinical benefit is known, such as mechanical heart valves, acute coronary syndrome, or recent insertion of coronary stents (2C)

- Test the INR more frequently after starting, stopping or changing the dose of concomitant medication

- Avoid frequent dose adjustments. A change in warfarin dose will take several days to influence the INR, so testing the INR within 24 or 48 hours of a dose change may not truly reflect the steady-state response to the dose adjustment

- Avoid excessive increases in dose when the INR drifts below the target INR range

- Effective patient education can minimise compliance problems

Pharmacogenetic testing to guide warfarin dosing is not necessary $\left(1 \mathrm{~B}^{22}\right)$

* Level of evidence in parentheses in bold. Details, Box 1. Recommendations with no evidence level are standard practice and not based on gradable evidence.

that its use improves outcome in life-threatening bleeds. Currently, phytomenadione is the only injectable formulation available in Australia and New Zealand. While intravenous or oral routes of administration can be used and are effective in reversing an INR that is raised because of warfarin therapy, the intravenous route achieves a more rapid response compared with oral administration, with an onset of action seen within 6-8 hours. However, both routes achieve a similar correction of INR by 24 hours. ${ }^{23}$

Vitamin $\mathrm{K}_{1}$ should not be administered by subcutaneous or intramuscular routes. Subcutaneous administration is no more effective than placebo, while intramuscular injection in an over-anticoagulated patient may lead to hae- 


\section{Characteristics of Prothrombinex-VF* and fresh frozen plasma}

\begin{tabular}{|c|c|c|}
\hline & Prothrombinex-VF ${ }^{\dagger}$ & Fresh frozen plasma ${ }^{\dagger}$ \\
\hline Description & $\begin{array}{l}\text { Prepared from plasma collected from voluntary donors. } \\
\text { Sterile freeze-dried powder containing coagulation factors } \\
\text { II, IX and X and low levels of factor VII }\end{array}$ & $\begin{array}{l}\text { Separated and frozen within } 18 \text { hours of collection from volunteer donors. } \\
\text { Contains all coagulation factors }\end{array}$ \\
\hline Contraindications & $\begin{array}{l}\text { Patients showing signs of thrombosis or disseminated } \\
\text { intravascular coagulation }\end{array}$ & $\begin{array}{l}\text { Do not use when coagulopathy can be corrected more effectively with } \\
\text { specific therapy, such as vitamin } \mathrm{K}_{1} \text {, cryoprecipitate or other specific factor } \\
\text { concentrates }\end{array}$ \\
\hline Specifications & $\begin{array}{l}\text { Available in vials containing } 500 \mathrm{IU} \text { of factor II, IX and X to } \\
\text { be reconstituted in } 20 \mathrm{~mL} \text { of water for injections. Each vial } \\
\text { also contains } 25 \mathrm{IU} \text { of antithrombin and } 192 \mathrm{IU} \text { of heparin }\end{array}$ & $\begin{array}{l}\text { Available in Australia in units of } 250-334 \mathrm{~mL} \text { and in New Zealand as } \\
180-300 \mathrm{~mL} \text { (typically } 240-275 \mathrm{~mL} \text { ). May be stored in monitored blood } \\
\text { refrigerator at } 2-6^{\circ} \mathrm{C} \text { for up to } 5 \text { days once thawed, and relabelled "thawed } \\
\text { plasma" in accordance with Australian and New Zealand Society of Blood } \\
\text { Transfusion Guidelines. Thawed plasma has levels of factors II, VII, IX and X } \\
\text { adequate for warfarin reversal }\end{array}$ \\
\hline Availability & From relevant blood service or hospital blood bank & From relevant blood service or hospital blood bank \\
\hline \multirow[t]{4}{*}{$\begin{array}{l}\text { Considerations } \\
\text { for use }\end{array}$} & No need to consider $\mathrm{ABO}$ blood group & $\begin{array}{l}\text { Available in all } A B O \text { blood groups and should be } A B O \text {-group compatible with } \\
\text { patient's red cells (or use AB plasma) }\end{array}$ \\
\hline & Known allergies to prothrombin complex concentrates & $\begin{array}{l}\text { Most common adverse events - allergic reactions and volume overload. } \\
\text { Potential for transfusion-related acute lung injury and other transfusion } \\
\text { reactions, including transmission of infections }\end{array}$ \\
\hline & $\begin{array}{l}\text { Predisposition to venous thrombosis, disseminated intra- } \\
\text { vascular coagulation and myocardial infarction }{ }^{\ddagger}\end{array}$ & \\
\hline & Heparin-induced thrombocytopenia & \\
\hline
\end{tabular}

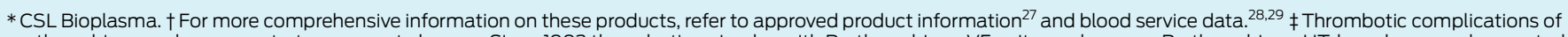

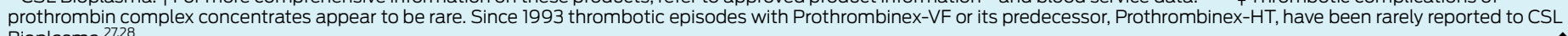
Bioplasma. ${ }^{27,28}$

matoma and bleeding, and its effect on reversal is unpredictable owing to variable absorption - it can be associated with a prolonged increase of vitamin $\mathrm{K}_{1}$ plasma levels, which may hinder re-anticoagulation. ${ }^{24,25}$ The major concern about intravenous vitamin $K_{1}$ has been anaphylaxis. Although the absolute incidence is unknown, it is most likely rare. There is no convincing association between anaphylaxis and dose, concentration or rate of administration of vitamin $\mathrm{K}_{1}$ but the literature suggests that current formulations with mixed micelles of lecithin and glycol are safer than the previous preparations containing polyethylated castor oil. ${ }^{26}$

\section{Prothrombin complex concentrate and fresh frozen plasma}

Replacement is necessary to correct the low levels of factors II, VII, IX and X induced by warfarin. This can be achieved by using a prothrombin complex concentrate (PCC) or fresh frozen plasma (FFP) (Box 3).

PCC are formulated with three factors (II, IX and X) or four factors (II, VII, IX and X). Advantages of PCC over FFP include rapid reconstitution into a small volume for infusion over 20-30 minutes, fast onset of action, no requirement to check a patient's blood group, minimal risk of viral transmission due to pathogen reduction and inactivation steps during manufacturing, ${ }^{27}$ and reduced risk of other clinical adverse reactions such as transfusion-associated circulatory overload or transfusion-associated acute lung injury. The latter is due to circulating antihuman leukocyte antigen or antigranulocyte antibodies in plasma. ${ }^{28,29}$ However, PCC does contain small amounts of heparin and its use to reverse warfarin anticoagulation should be carefully considered in patients with heparin-induced thrombocytopenia. ${ }^{27}$
Prothrombinex-VF, a three-factor PCC, is the only product currently in routine use in Australia and New Zealand for warfarin reversal. Due to its low levels of factor VII, the Warfarin Reversal Consensus Guidelines published in 2004 recommended that it be supplemented with FFP. ${ }^{11}$ Since that time, there have been several reports of the successful use of a three-factor concentrate without addition of FFP. $^{30-33}$ Prothrombinex-VF has been used successfully to electively reverse anticoagulation in patients on warfarin therapy with a stable INR, and achieved the target INR in over $90 \%$ of patients. ${ }^{30}$ However, this study included few patients $(14 \%)$ with INR $>3.5$ requiring normalisation of the INR. Patients with major or life-threatening bleeding or INR $>10.0$ accompanied by high risk of bleeding are of great concern to clinicians, and the efficacy of Prothrombinex-VF when used alone in these patients has not been extensively evaluated. In such patients, supplementing factor VII by administering FFP should ensure optimal reversal of the anticoagulant effect of warfarin.

The previous Warfarin Reversal Consensus Guidelines recommended three-factor PCC (Prothrombinex-HT) be administered at a dose range of $25-50 \mathrm{IU} / \mathrm{kg} .{ }^{11}$ The revised dosing recommendations for various clinical scenarios included in this update are based on panel consensus alone (ie, rather than gradable evidence). The suggested dose of Prothrombinex-VF for reversal of the anticoagulant effect of warfarin is based on initial and target INRs (Box 4). ${ }^{30}$

Prothrombinex-VF is able to completely reverse an excessive INR within 15 minutes, but the infused clotting factors have half-lives similar to endogenous clotting factors. Therefore, vitamin $\mathrm{K}_{1} 5-10 \mathrm{mg}$ should be given intravenously with the PCC to sustain the reversal effect. 
4 Suggested dose of Prothrombinex-VF to reverse the anticoagulant effect of warfarin according to initial and target international normalised ratio (INR)*

\begin{tabular}{l|cccc} 
& \multicolumn{4}{|c}{ Initial INR } \\
\hline Target INR & $1.5-2.5$ & $2.6-3.5$ & $3.6-10.0$ & $>10.0$ \\
$0.9-1.3$ & $30 \mathrm{IU} / \mathrm{kg}$ & $35 \mathrm{IU} / \mathrm{kg}$ & $50 \mathrm{IU} / \mathrm{kg}$ & $50 \mathrm{IU} / \mathrm{kg}$ \\
$1.4-2.0$ & $15 \mathrm{IU} / \mathrm{kg}$ & $25 \mathrm{IU} / \mathrm{kg}$ & $30 \mathrm{IU} / \mathrm{kg}$ & $40 \mathrm{IU} / \mathrm{kg}$ \\
\hline
\end{tabular}

* Table reproduced with permission from Intern Med J 2011; 41: 337-343. ${ }^{30}$

FFP contains all coagulation factors present in whole blood but it is not a factor concentrate, and multiple units may be needed if FFP alone is used for warfarin reversal. In addition to the inherent risks of plasma use mentioned already, requirements for its use include the need to determine the patient's blood group (or to use group $A B$ plasma), appropriate facilities for frozen plasma storage and thawing, and the time taken for infusion. Therefore, FFP should not be used routinely to reverse warfarin anticoagulation; however, where PCC is unavailable and emergency reversal is required, FFP should be used, along with vitamin $\mathrm{K}_{1}$ to sustain the reversal effect.

\section{Treating a patient with bleeding, regardless of INR}

For patients on warfarin therapy with bleeding in whom the aim is to normalise the INR, vitamin $\mathrm{K}_{1}$ given intravenously is the preferred treatment because of its faster and predictable onset of action. For this indication, doses $\leqslant 3 \mathrm{mg}$ are ineffective. Consistent with other guidelines, we recommend a dose of 5-10 mg. ${ }^{25,34,35}$ Our recommendations for managing patients on warfarin therapy with bleeding are summarised in Box 5. For life-threatening (critical organ) and clinically significant bleeds, the consensus is to use the maximum dose of Prothrombinex-VF (with vitamin $\mathrm{K}_{1}$ and FFP) and the maximum amount of FFP when Prothrombinex-VF is unavailable.

\section{Treating patients with high INR and no bleeding}

Among patients with an elevated INR up to 10.0 who do not have bleeding or risk factors for major bleeding, it has been shown that oral administration of low-dose vitamin $\mathrm{K}_{1}$ does not lower the risk of bleeding compared with placebo and should not be used routinely. ${ }^{36}$ However, for patients with risk factors for bleeding, vitamin $\mathrm{K}_{1} 1-2 \mathrm{mg}$ orally or $0.5-$ $1.0 \mathrm{mg}$ intravenously should be considered. Risk factors for major bleeding include a major bleed within the previous 4 weeks, surgery within the previous 2 weeks, a platelet count less than $50 \times 10^{9} / \mathrm{L}$, known liver disease or concurrent antiplatelet therapy. There are no randomised studies to guide management of patients whose INR exceeds 10.0 and who are not bleeding. A recent single-arm study involving outpatients with an INR greater than 10.0 reported a low rate of major bleeding when these patients received $2.5 \mathrm{mg}$ of oral vitamin $\mathrm{K}_{1} \cdot{ }^{37}$ Our recommendations for managing patients with high INR and no bleeding are summarised in Box 6. Many patients on warfarin are outpatients and information on individual patient bleeding risk is frequently not available to laboratory staff who are involved in reporting elevated INR results and attempting to communicate results to patients. In these settings, good communication between clinical and laboratory staff is essential.

\section{Management of patients on warfarin therapy with bleeding*}

Clinical setting Recommendations and levels of evidence ${ }^{\dagger}$

INR $\geqslant 1.5$ with life- Cease warfarin therapy and administer:

threatening ${ }^{\ddagger}$

(critical organ)

bleeding

- vitamin $\mathrm{K}_{1}$ 5.0-10.0 mg IV (2C)

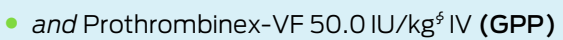

- and fresh frozen plasma 150-300 mL (GPP)

- If Prothrombinex-VF is unavailable, administer fresh frozen plasma $15 \mathrm{~mL} / \mathrm{kg}$ (GPP)

INR $\geqslant 2.0$ with

clinically

significant

bleeding (not life-

threatening)

- Cease warfarin therapy and administer:

- vitamin $\mathrm{K}_{1}$ 5.0-10.0 mg IV (2C)

- and Prothrombinex-VF 35.0-50.0 IU/kg IV (GPP) according to INR (see Box 4)

- If Prothrombinex-VF is unavailable, administer fresh frozen plasma $15 \mathrm{~mL} / \mathrm{kg}$ (GPP)

Any INR with minor bleeding

- Omit warfarin, repeat INR the following day and adjust warfarin dose to maintain INR in the target therapeutic range (2C)

- If bleeding risk is high ${ }^{9}$ or INR > 4.5, consider vitamin $\mathrm{K}_{1}$, 1.0-2.0 mg orally or 0.5-1.0 mg IV (GPP)

INR = international normalised ratio. IV = intravenously. * Indication for warfarin therapy should be reviewed; if clinically appropriate, consider permanent cessation. † Level of evidence in parentheses in bold. Details, Box 1. ‡ Includes intracranial bleeding. \$ Consider administering a Prothrombinex-VF dose less than $50.0 \mathrm{IU} / \mathrm{kg}$ when INR 1.5-1.9. Я Recent major bleed (within previous 4 weeks) or major surgery (within previous 2 weeks), thrombocytopenia (platelet count, $<50 \times 10^{9} / \mathrm{L}$ ), known liver disease or concurrent antiplatelet therapy.

\section{Management of patients on warfarin therapy with high INR and no bleeding}

Clinical setting

INR higher than the therapeutic range but $<4.5$ and no bleeding

INR 4.5-10.0 and no bleeding

INR $>10.0$ and no bleeding

\section{Recommendations and levels of evidence*}

Lower or omit the next dose of warfarin

Resume therapy at a lower warfarin dose when the INR approaches therapeutic range

- If the INR is only minimally above therapeutic range (up to $10 \%$ ) dose reduction is generally not necessary (2C)

- Cease warfarin therapy; consider reasons for elevated INR and patient-specific factors. Vitamin $\mathrm{K}_{1}$ is usually unnecessary (2C)

- If bleeding risk is high: ${ }^{\dagger}$

- consider vitamin $\mathrm{K}_{1} 1.0-2.0 \mathrm{mg}$ orally or $0.5-1.0 \mathrm{mg}$ IV (GPP)

- measure INR within $24 \mathrm{~h}$

- resume warfarin at a reduced dose once INR approaches therapeutic range

- Cease warfarin therapy, administer 3.0-5.0 mg vitamin $\mathrm{K}_{1}$ orally or $\mathrm{IV}^{\ddagger}(2 \mathrm{C})$

- Measure INR in 12-24 h. Close monitoring of INR daily to second daily over the following week (GPP)

- Resume warfarin therapy at a reduced dose once INR approaches therapeutic range

- If bleeding risk is high: ${ }^{\dagger}$

- consider Prothrombinex-VF, 15-30 IU/kg (GPP)

- measure INR in 12-24h. Close monitoring over the following week

- resume warfarin therapy at a reduced dose once INR approaches therapeutic range

INR = international normalised ratio. IV = intravenously. * Level of evidence in parentheses in bold; details, Box 1. Recommendations with no evidence level are standard practice and not based on gradable evidence. † Recent major bleed (within previous 4 weeks) or major surgery (within previous 2 weeks), thrombocytopenia (platelet count, $<50 \times 10^{9} / \mathrm{L}$ ), known liver disease or concurrent antiplatelet therapy. $¥$ Extrapolated from oral vitamin $\mathrm{K}$ data in absence of IV data. 


\section{Suggested perioperative arterial and venous thromboembolism risk stratification*}

\begin{tabular}{|c|c|c|c|}
\hline Risk group & Atrial fibrillation & Venous thromboembolism & Mechanical heart valves \\
\hline \multirow[t]{3}{*}{ High } & $\mathrm{CHADS}_{2}$ score 5-6 & Recent VTE ( $<3$ months previously) & $\begin{array}{l}\text { Any mechanical mitral valve or older aortic } \\
\text { heart valves (eg, caged-call) }\end{array}$ \\
\hline & Recent stroke or TIA (<3 months previously) & High-risk thrombophilia $^{\dagger}$ & Recent stroke or TIA (<3 months previously) \\
\hline & Rheumatic valvular heart disease & & \\
\hline \multirow[t]{2}{*}{ Moderate } & \multirow[t]{2}{*}{$\mathrm{CHADS}_{2}$ score $3-4$} & Recurrent VTE & \multirow{2}{*}{$\begin{array}{l}\text { Bileaflet aortic valve prosthesis with one or } \\
\text { more risk factors }{ }^{\ddagger}\end{array}$} \\
\hline & & VTE within last 3-12 months & \\
\hline Low & $\mathrm{CHADS}_{2}$ score $0-2$ (no previous TIA or stroke) & VTE $>12$ months previously & $\begin{array}{l}\text { Bileaflet aortic heart valve without any risk } \\
\text { factors }\end{array}$ \\
\hline
\end{tabular}

\section{Pre- and postoperative management of warfarin anticoagulation}

When considering how to manage patients receiving warfarin who need surgery, it is important to consider the risk of thrombosis if warfarin is temporarily stopped, relative to the risk of bleeding if it is continued or modified. The perioperative thrombosis risk is determined by the indication for warfarin and the type of surgery, particularly with respect to postoperative VTE. Patients with MHV, AF with a history of stroke or transient ischaemic attack (TIA) or with multiple risk factors CHADS $_{2}$ score [congestive heart failure, hypertension, age $\geqslant 75$ years, diabetes, 1 point each; prior stroke or transient ischaemic attack, 2 points] $>2$, including a history of stroke or TIA), or an episode of VTE within the previous 3 months can be considered as high risk. Box 7 shows our adapted version of a recently published empirical risk stratification scheme for arterial and venous thromboembolism. ${ }^{38}$

Bleeding risk is high with cardiac, neurosurgical, cancer-related, orthopaedic or urological operations, and also with certain otherwise minor procedures like colonic polypectomy.

8 Management of patients on long-term warfarin therapy undergoing invasive procedures

Recommendations*

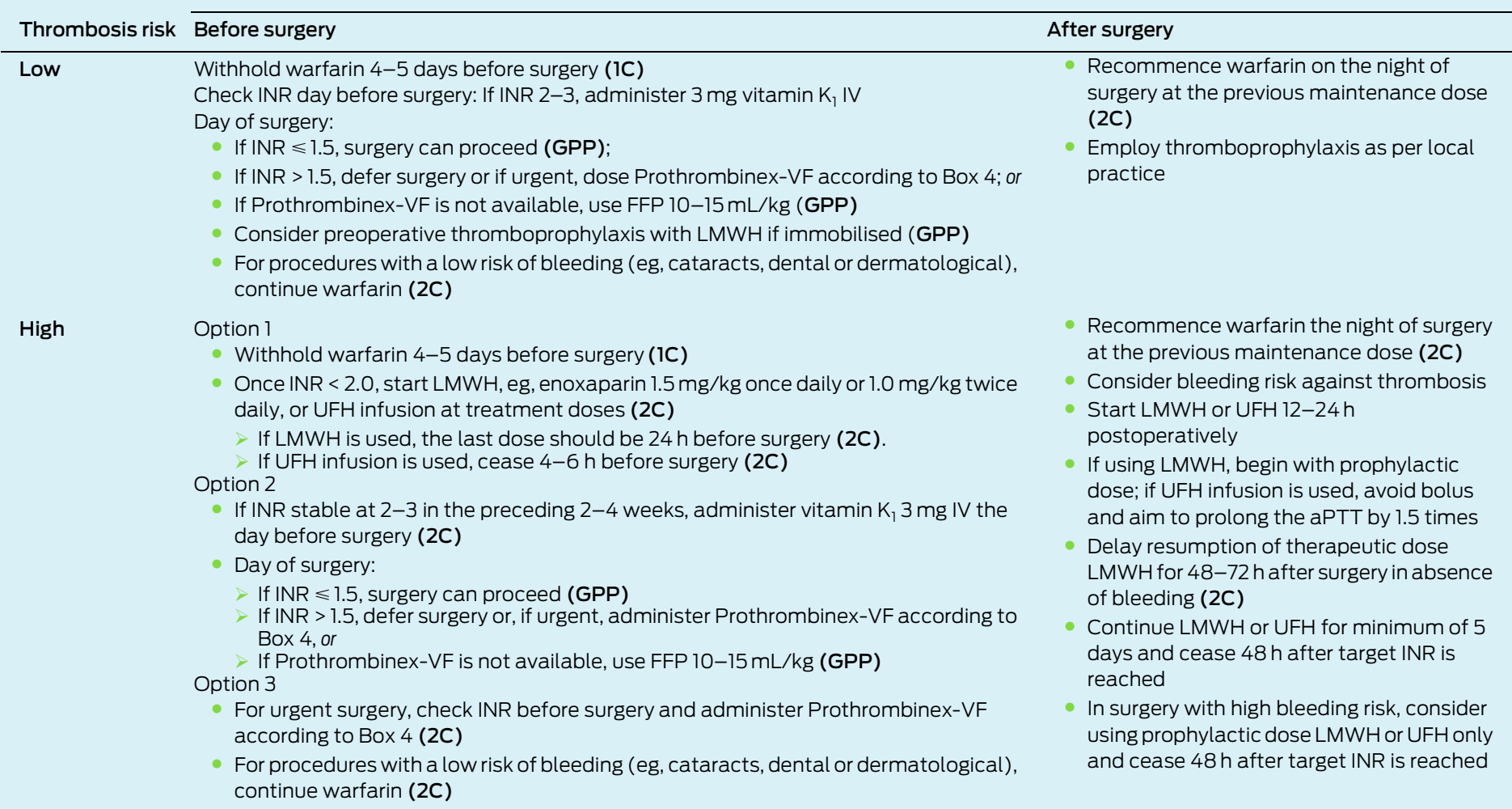

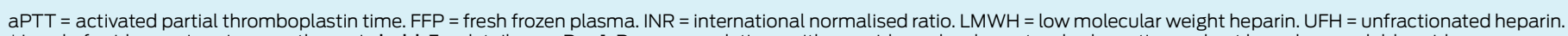
$*$ Level of evidence given in parentheses in bold. For details, see Box 1. Recommendations with no evidence level are standard practice and not based on gradable evidence. 
Patients at high risk for arterial and venous thromboembolism should be considered for bridging anticoagulation with therapeutic low molecular weight heparin (LMWH) or an infusion of unfractionated heparin. ${ }^{39}$ Bridging may include a heparin before and/or after surgery. It should be noted that quality evidence is lacking to show that bridging with heparin reduces arterial thromboembolism in patients with AF but is associated with increased bleeding (see below). Bridging is usually not needed in patients with low-risk AF ( $\mathrm{CHADS}_{2}$ score 0-2 and no history of TIA or stroke), or VTE occurring more than 3 months before surgery.

Bridging with a heparin is associated with an added risk of surgical bleeding that varies depending on the type of surgery (20\% with major surgery, compared with $0.7 \%$ with minor surgery). ${ }^{40}$ The risk of bleeding should be considered in the context of the severe consequences of thromboembolic stroke (death in $40 \%$ and severe disability in $30 \%$ of patients).

Traditionally, warfarin has been stopped 5 days before a major operation. Surgery can proceed safely if the INR is $<1.5$ on the day of surgery. To avoid cancellations because the INR is above this level, the INR can be checked on the day before surgery and vitamin $\mathrm{K}_{1}$ can be administered if needed. In patients who are given heparin before surgery, an LMWH is usually started when the INR is $<2.0$ (typically on the third morning after the last warfarin dose) and continued until 24 hours before surgery; some guidelines recommend halving the last dose of LMWH before surgical procedures associated with a high bleeding risk. ${ }^{41}$

The above method can be labour intensive. In patients with a stable INR of 2.0-3.0 during the preceding 4 weeks, vitamin $\mathrm{K}_{1} 3 \mathrm{mg}$ given intravenously on the evening (12-18 hours) before surgery has been shown to be effective in achieving a preoperative INR of $<1.5$ in $94 \%$, with few episodes of major bleeding related to surgery and low rates of warfarin resistance when restarting the drug. ${ }^{42}$ Both methods using vitamin $\mathrm{K}_{1}$ to reverse warfarin anticoagulation often require hospital in the home services or a general practitioner to administer the subcutaneous LMWH or intravenous vitamin $\mathrm{K}_{1}$, and can result in higher rates of cancellation of surgery if the INR is $>1.5$ on the day of surgery.

For patients who need urgent surgery while receiving warfarin therapy, three-factor PCC can effectively reverse the anticoagulant effect. ${ }^{30,31}$ PCC should not be used routinely to enable elective surgery however, as vitamin $\mathrm{K}_{1}$ is effective and less costly.

Many dental, dermatological or ophthalmological procedures are associated with a low bleeding risk. Patients with a low bleeding risk need not stop warfarin.

Bleeding risk can be minimised after major surgery by adjusting the time when anticoagulant is resumed, according to the anticipated surgical bleeding risk and the extent of intraoperative or immediate postoperative bleeding. This means that therapeutic LMWH is delayed for $48-72$ hours or substituted with prophylactic LMWH in patients having major surgery with a high bleeding risk. ${ }^{43}$ Bleeding risk is low after minor procedures if therapeutic LMWH is started about 24 hours after surgery. Warfarin can be restarted on the evening of surgery at the previous maintenance dose if there is adequate surgical haemostasis.

The strategies that can be used to manage patients on long-term warfarin therapy during surgery and other invasive procedures are summarised in Box 8 . These strategies are not associated with a delay in re-establishing a therapeutic INR when resuming warfarin after surgery.

Competing interests: A restricted educational grant from CSL Bioplasma that was administered by the ASTH enabled the Warfarin Reversal Consensus Group (WRCG) to travel to meet, develop and write these guidelines. No members of the WRCG received honoraria. Paul Harper is a Director of INR Online, an online warfarin management system, and a member of the Bayer HealthCare rivaroxaban New Zealand advisory committee Erica Wood is a member of the Transfusion Outcomes Research Collaborative which operates the Massive Transfusion and Critical Bleeding Registry through Monash University. CSL Limited, the manufacturers of Prothrombinex-VF, have provided financial support to this registry.

Provenance: Not commissioned; externally peer reviewed.

1 Linkins LA, Choi PT, Douketis JD. Clinical impact of bleeding in patients taking oral anticoagulant therapy for venous thromboembolism: a meta-analysis. Ann Intern Med 2003; 139: 893-900.

2 Kearon C, Akl EA, Comerota AJ, et al. Antithrombotic therapy for VTE disease: antithrombotic therapy and prevention of thrombosis, 9th ed: American College of Chest Physicians Evidence-Based Clinical Practice Guidelines. Chest 2012;141 (2 Suppl): e419S-e494S.

3 Gallus AS, Baker RI, Chong BH, et al. Consensus guidelines for warfarin therapy. Recommendations from the Australasian Society of Thrombosis and Haemostasis. Med J Aust 2000; 172: 600-605.

4 Schulman S, Beyth RJ, Kearon C, Levine MN. Hemorrhagic complications of anticoagulant and thrombolytic treatment: American College of Chest Physicians Evidence-Based Clinical Practice Guidelines (8th Edition). Chest 2008; 133 (6 Suppl): 257S-298S.

5 Whitlock RP, Sun JC, Fremes SE, et al. Antithrombotic and thrombolytic therapy for valvular disease: antithrombotic therapy and prevention of thrombosis, 9th ed: American College of Chest Physicians Evidence-Based Clinical Practice Guidelines. Chest 141 (2 Suppl): e576S-600S.

6 Connolly SJ, Ezekowitz MD, Yusuf S, et al; RE-LY Steering Committee and Investigators. Dabigatran versus warfarin in patients with atrial fibrillation. NEngl J Med 2009; 361: 1139-1151.

7 Granger CB, Alexander JH, McMurray JJ, et al; ARISTOTLE Committees and Investigators. Apixaban versus warfarin in patients with atrial fibrillation. NEngl J Med 2011; 365: 981-992.

8 Patel MR, Mahaffey KW, Garg J, et al; ROCKET AF Investigators. Rivaroxaban versus warfarin in nonvalvular atrial fibrillation. NEngl J Med 2011; 365: 883-891.

9 Eerenberg ES, Kamphuisen PW, Sijpkens MK, et al. Reversal of rivaroxaban and dabigatran by prothrombin complex concentrate: a randomized, placebocontrolled, crossover study in healthy subjects. Circulation 2011; 124: 1573-1579.

10 Eikelboom JW, Wallentin L, Connolly SJ, et al. Risk of bleeding with 2 doses of dabigatran compared with warfarin in older and younger patients with atrial fibrillation: an analysis of the randomized evaluation of long-term anticoagulant therapy (RE-LY) trial. Circulation 2011; 123: 2363-2372.

11 Baker RI, Coughlin PB, Gallus AS, et al. Warfarin Reversal Consensus Group. Warfarin reversal: consensus guidelines, on behalf of the Australasian Society of Thrombosis and Haemostasis. Med J Aust 2004; 181: 492-497.

12 Guyatt GH, Norris SL, Schulman S, et al. Methodology for the development of antithrombotic therapy and prevention of thrombosis guidelines: antithrombotic therapy and prevention of thrombosis, 9th ed: American College of Chest Physicians Evidence-Based Clinical Practice Guidelines. Chest 2012; 141 (2 Suppl): 53S-70S.

13 Palareti G, Leali N, Coccheri S, et al. Bleeding complications of oral anticoagulant treatment: an inception-cohort, prospective collaborative study (ISCOAT). Italian Study on Complications of Oral Anticoagulant Therapy. Lancet 1996; 348: 423-428.

14 A randomized trial of anticoagulants versus aspirin after cerebral ischemia of presumed arterial origin. The Stroke Prevention in Reversible Ischemia Trial (SPIRIT) Study Group. Ann Neurol 1997; 42: 857-865.

15 White RH, Beyth RJ, Zhou H, Romano PS. Major bleeding after hospitalization for deep-venous thrombosis. Am J Med 1999; 107: 414-424.

16 van der Meer FJ, Rosendaal FR, Vandenbroucke JP, Briët E. Bleeding complications in oral anticoagulant therapy. An analysis of risk factors. Arch Intern Med 1993; 153: 1557-1562.

17 Landefeld CS, Beyth RJ. Anticoagulant-related bleeding: clinical epidemiology, prediction, and prevention. Am J Med 1993; 95: 315-328.

18 Camm AJ, Kirchhof P, Lip GY, et al. Guidelines for the management of atrial fibrillation: the Task Force for the Management of Atrial Fibrillation of the European Society of Cardiology (ESC). Eur Heart J 2010; 31: 2369-2429.

19 Harrison L, Johnston M, Massicotte MP, et al. Comparison of 5-mg and 10-mg loading doses in initiation of warfarin therapy. Ann Intern Med 1997; 126: 133-136. 
20 Crowther MA, Ginsberg JB, Kearon C, et al. A randomized trial comparing 5-mg and 10-mg warfarin loading doses. Arch Intern Med 1999; 159: 46-48.

21 Kovacs MJ, Rodger M, Anderson DR, et al. Comparison of 10-mg and 5-mg warfarin initiation nomograms together with low-molecular-weight heparin for outpatient treatment of acute venous thromboembolism. A randomized, double-blind, controlled trial. Ann Intern Med 2003; 138: 714-719.

22 Holbrook A, Schulman S, Witt DM, et al. Evidence-based management of anticoagulant therapy: antithrombotic therapy and prevention of thrombosis, 9th ed: American College of Chest Physicians Evidence-Based Clinical Practice Guidelines. Chest 2012; 141 (2 Suppl): el52S-184S.

23 Watson HG, Baglin T, Laidlaw SL, et al. A comparison of the efficacy and rate of response to oral and intravenous vitamin $\mathrm{K}$ in reversal of over-anticoagulation with warfarin. Br J Haematol 2001; 115: 145-149.

24 Soedirman JR, De Bruijn EA, Maes RA, et al. Pharmacokinetics and tolerance of intravenous and intramuscular phylloquinone (vitamin $\mathrm{Kl}$ ) mixed micelles formulation. Br J Clin Pharmacol 1996; 41: 517-523.

25 Dezee KJ, Shimeall WT, Douglas KM, et al. Treatment of excessive anticoagulation with phytonadione (vitamin K): a meta-analysis. Arch Intern Med 2006; 166: 391-397.

26 Fiore LD, Scola MA, Cantillon CE, Brophy MT. Anaphylactoid reactions to vitamin K. J Thromb Thrombolysis 2001; 11: 175-183.

27 CSL Bioplasma. Prothrombinex-VF product information. Melbourne: CSL Limited, 2011.

28 Australian Red Cross Blood Service. Blood component information: circular of information 2012. http://www.transfusion.com.au/sites/default/files/ BCI\%20290512\%20FIN.pdf (accessed Dec 2012).

29 New Zealand Blood. Frozen plama components. Blood component datasheet: plasma fresh frozen leucocyte depleted. 2010. http://www.nzblood.co.nz/ Clinical-information/Transfusion-medicine/Health-professionals-medicinedatasheets/Frozen-plasma-components (accessed Dec 2012).

$30 \mathrm{Tran} \mathrm{H}$, Collecutt M, Whitehead S, Salem HH. Prothrombin complex concentrates used alone in urgent reversal of warfarin anticoagulation. Intern Med J 2011; 41: 337-343.

31 Chiu D, Grigg M, Levi E. Operating on patients with warfarin: simpler alternative approach [letter]. ANZ J Surg 2009; 79: 409-410.

32 Crawford JH, Augustson BM. Prothrombinex use for the reversal of warfarin: is fresh frozen plasma needed [letter]? Med J Aust 2006; 184: 365-366.
33 Imberti D, Barillari G, Biasioli C, et al. Emergency reversal of anticoagulation with a three-factor prothrombin complex concentrate in patients with intracranial haemorrhage. Blood Transfus 2011; 9: 148-155.

34 Keeling D, Baglin T, Tait C, et al; British Committee for Standards in Haematology. Guidelines on oral anticoagulation with warfarin - fourth edition. Br J Haematol 2011; 154: 311-324.

35 Ansell J, Hirsh J, Hylek E, et al. Pharmacology and management of the vitamin $\mathrm{K}$ antagonists: American College of Chest Physicians Evidence-Based Clinical Practice Guidelines (8th Edition). Chest 2008; 133 (6 Suppl): 160S-198S.

36 Crowther MA, Ageno W, Garcia D, et al. Oral vitamin K versus placebo to correct excessive anticoagulation in patients receiving warfarin: a randomized trial. Ann Intern Med 2009; 150: 293-300.

37 Crowther MA, Garcia D, Ageno W, et al. Oral vitamin K effectively treats international normalised ratio (INR) values in excess of 10. Results of a prospective cohort study. Thromb Haemost 2010; 104: 118-121.

38 Douketis JD. Perioperative management of patients who are receiving warfarin therapy: an evidence-based and practical approach. Blood 2011; 117: 5044-5049.

39 Spyropoulos AC, Turpie AG, Dunn AS, et al; REGIMEN Investigators. Clinical outcomes with unfractionated heparin or low-molecular-weight heparin as bridging therapy in patients on long-term oral anticoagulants: the REGIMEN registry. J Thromb Haemost 2006; 4: 1246-1252.

40 Dunn AS, Spyropoulos AC, Turpie AG. Bridging therapy in patients on long-term oral anticoagulants who require surgery: the Prospective Peri-operative Enoxaparin Cohort Trial (PROSPECT). J Thromb Haemost 2007; 5: 2211-2218.

41 Douketis JD, Berger PB, Dunn AS, et al. The perioperative management of antithrombotic therapy: American College of Chest Physicians Evidence-Based Clinical Practice Guidelines (8th Edition). Chest 2008; 133 (6 Suppl): 299S339S.

42 Burbury KL, Milner A, Snooks B, et al. Short-term warfarin reversal for elective surgery--using low-dose intravenous vitamin $\mathrm{K}$ : safe, reliable and convenient*. Br J Haematol 2011; 154: 626-634.

43 Kovacs MJ, Kearon C, Rodger M, et al. Single-arm study of bridging therapy with low-molecular-weight heparin for patients at risk of arterial embolism who require temporary interruption of warfarin. Circulation 2004; 110: 1658-1663. 